\title{
Organizing pneumonia associated with Sjogren's syndrome: a comment
}

\author{
Sheng-Yuan Ruan · Yao-Wen Kuo
}

Received: 13 August 2008 / Accepted: 21 October 2008 / Published online: 7 November 2008

(C) Springer-Verlag 2008

\section{Dear Editor-in-Chief,}

We read with interest the recent case report by Ioannou et al. [1] about organizing pneumonia (OP) in a patient with primary Sjogren's syndrome. The term "cryptogenic organizing pneumonia" used in the case report is inappropriate. Several clinical settings have been known to be associated with organizing pneumonia pattern, including infectious etiologies, collagen vascular diseases, drug reactions, and idiopathic process [2]. However, according to the consensus statement of the American Thoracic Society (ATS) and the European Respiratory Society (ERS) for classification of the idiopathic interstitial pneumonias in 2001, the diagnosis of cryptogenic organizing pneumonia (COP) is reserved for isolated organizing pneumonia in patients without any identifiable associated diseases [2]. By this new definition, the diagnosis of "cryptogenic organizing pneumonia" in the article of Ioannou et al. had better be changed to "organizing pneumonia", to prevent confusion. While reading relevant articles, one should be cautious about the difference in definition of interstitial pneumonias before and after the new ATS/ERS consensus statement published in 2001.

In addition, the authors also mentioned about the common pulmonary manifestations of primary Sjogren's syndrome in the discussion section. They concluded by a

S.-Y. Ruan $(\square)$

Division of Pulmonary Medicine,

Department of Internal Medicine,

National Taiwan University Hospital Yun-Lin Branch,

No. 579, Yun-Lin Sec. 2 Road, Douliou City, Yun-Lin, Taiwan

e-mail: syruan@ntu.edu.tw

Y.-W. Kuo

Department of Internal Medicine,

National Taiwan University Hospital, Taipei, Taiwan pathologic study that non-specific interstitial pneumonitis (NSIP) is the commonest form of interstitial lung disease caused by Sjogren's syndrome [3]. However, it is not appropriate to make such a conclusion according to the current evidence. Lymphoid interstitial pneumonia (LIP) is also considered as an important form of interstitial lung diseases associated with Sjogren's syndrome [4, 5]. More studies are needed to clarify the aforementioned issue.

\section{References}

1. Ioannou S, Toya SP, Tomos P, Tzelepis GE (2008) Cryptogenic organizing pneumonia associated with primary Sjogren's syndrome. Rheumatol Int 28:1053-1055. doi:10.1007/s00296-0080568-x

2. American Thoracic Society/European Respiratory Society (2002) American Thoracic Society/European Respiratory Society international multidisciplinary consensus classification of the idiopathic interstitial pneumonias. Am J Respir Crit Care Med 165:277-304

3. Ito I, Nagai S, Kitaichi M, Nicholson AG, Johkoh T, Noma S et al (2005) Pulmonary manifestations of primary Sjogren's syndrome: a clinical, radiologic, and pathologic study. Am J Respir Crit Care Med 171:632-638. doi:10.1164/rccm.200403-417OC

4. Strimlan CV, Rosenow EC III, Divertie MB, Harrison EG Jr (1976) Pulmonary manifestations of Sjogren's syndrome. Chest 70:354361. doi:10.1378/chest.70.3.354

5. Taouli B, Brauner MW, Mourey I, Lemouchi D, Grenier PA (2002) Thin-section chest CT findings of primary Sjogren's syndrome: correlation with pulmonary function. Eur Radiol 12:1504-1511. doi:10.1007/s00330-001-1236-7 